\title{
Recrystallization and grain growth of a nano/ultrafine structured austenitic stainless steel during annealing under high hydrostatic pressure
}

\author{
Agnieszka Teresa Krawczynska ${ }^{1, \star}$ (D), Stanislaw Gierlotka ${ }^{2}$, Przemyslaw Suchecki ${ }^{1}$, Daria Setman ${ }^{3}$, \\ Boguslawa Adamczyk-Cieslak ${ }^{1}$, Malgorzata Lewandowska ${ }^{1}$, and Michael Zehetbauer ${ }^{3}$ \\ ${ }^{1}$ Faculty of Materials Science and Engineering, Warsaw University of Technology, Woloska 141, 02-507 Warsaw, Poland \\ ${ }^{2}$ Institute of High Pressure Physics UNIPRESS, Polish Academy of Sciences, Sokolowska 29/37, 01-142 Warsaw, Poland \\ ${ }^{3}$ Faculty of Physics, University of Vienna, Boltzmanngasse 5, 1090 Vienna, Austria
}

Received: 20 December 2017

Accepted: 14 May 2018

Published online:

21 May 2018

(C) The Author(s) 2018

\begin{abstract}
The aim of this study was to investigate the effect of high hydrostatic pressure applied during annealing on the processes of recrystallization and grain growth in nanostructured austenitic stainless steel 316LVM. The nanostructures were obtained by profile rolling to a total strain of 3.4 and by high-pressure torsion to a total strain of 79 . These processes resulted in microstructures consisting of nanotwins and nanograins, respectively. The deformed samples were annealed at $900{ }^{\circ} \mathrm{C}$ for 10 min under atmospheric or hydrostatic pressures of 2 and $6 \mathrm{GPa}$. The resulting microstructures were examined using transmission and scanning electron microscopy techniques. The mechanical properties were evaluated in microhardness measurements. It was established that annealing under high hydrostatic pressure retards recrystallization and grain growth, both in profilerolled and high-pressure torsion-processed samples. The magnitude of retardation depends on the character of the grain boundaries. The non-equilibrium high-angle grain boundaries present in the high-pressure torsion-processed sample show higher mobility under pressure than the nanotwinned and lowangle boundaries in the profile-rolled sample.
\end{abstract}

\section{Introduction}

Recovery, recrystallization and grain growth are some of the most important processes that affect the properties of crystalline materials. For this reason, many papers have been devoted to understanding these phenomena in microcrystalline [1, 2], and recently in nanocrystalline, materials [3-5]. During the annealing of nanocrystalline materials produced by severe plastic deformation (SPD) techniques, one can observe typical processes of recovery, recrystallization and grain growth, but they follow a different course than in materials deformed by conventional techniques [6-8]. In general, nanomaterials are less

Address correspondence to E-mail: akrawczynska@wp.pl; agnieszka.krawczynska@pw.edu.pl 
thermally stable than their microcrystalline counterparts, and recrystallization begins below their usual recrystallization temperatures. However, it has also been shown that, by creating uniform nanostructures having a uniform grain size distribution and a high content of high-angle grain boundaries, thermal stability can be significantly improved [9-11]. The enhanced thermal stability of a nanostructured austenitic stainless steel can be obtained by adding yttrium powders during mechanical milling [12]. The addition of $1.5 \mathrm{wt} \%$ stabilizes the microstructure around $116 \mathrm{~nm}$ grain size after $3 \mathrm{~h}$ annealing at $1100{ }^{\circ} \mathrm{C}$. Moreover, the creation of deformation-induced nanotwins makes the microstructure stable up to $800{ }^{\circ} \mathrm{C}$ [13]. The processes of recrystallization and grain growth in nanostructured, and especially single-phased, materials have been quite well described. Nevertheless, one issue which remains almost completely neglected is how such materials behave during annealing under high hydrostatic pressure. This subject has been raised only in the author's previous work [14, 15]. In those studies, annealing under high hydrostatic pressure was applied to a hydrostatically extruded (HE) austenitic stainless steel to optimize its mechanical properties, particularly its strength to ductility balance. It was possible to achieve a controlled slowing of recrystallization processes to produce a nanostructured austenitic stainless steel possessing a good combination of strength and ductility (an ultimate tensile strength of $1247 \mathrm{MPa}$ and a total elongation of $24.4 \%$ ). The only experiments that have been performed under high pressure recently refer to the $\mathrm{Ge}$ precipitation rate in $\mathrm{Ge}+$ ion-implanted $\mathrm{SiO}_{2}$ films [16], a study on the effect of annealing under pressure on the material properties of $\mathrm{Cu} 2 \mathrm{ZnSn}(\mathrm{S}, \mathrm{Se}) 4$ thin films [17] and an enhancement of magnetic refrigeration performance in metamagnetic $\mathrm{MnCoSi}$ alloy by high-pressure annealing [18].

However, several authors have studied the effect of hydrostatic pressure on diffusion, dislocation climb and glide, recrystallization and grain growth mobility in microcrystalline materials [19-27]. It is well known that high hydrostatic pressure has an impact on diffusion processes that are correlated with the motion of vacancies, as it affects the activation volume $V^{*}$ of the crystal related to atomic rearrangements during thermally activated processes. The influence of pressure on $V^{*}$ can be expressed by the equation:
$V *=-R T \ln (v) / p$

where $R$ is the gas constant, $v$ is the rate of the processes investigated and $p$ is the pressure.

Furthermore, it was found during annealing of cold-rolled copper under a pressure of $4.2 \mathrm{GPa}$ that the pressure retarded recrystallization [20]. The general conclusion that can be drawn from this work regarding grain growth is that the higher the hydrostatic pressure applied, the more significant the decrease in grain boundary mobility. Moreover, the impact of high pressure on the $\langle 100\rangle,<110\rangle$ and $<111>$ tilt boundaries was analyzed [18, 22]. The results showed that the movement of $<110\rangle$ tilt boundaries depends on the activation energy, as this movement is effected by the cooperative motion of several atoms. The movement of the $\langle 100\rangle$ and $<111>$ tilt boundaries is not related to the activation energy and is effected by a single atom mechanism. It was also noticed during experiments on normal grain growth in aluminum under high hydrostatic pressure that the migration of low-angle grain boundaries was slowed down even more, nearly frozen in comparison with the case of general grain boundaries [26]. This is because low-angle grain boundaries can migrate by vacancy grain boundary migration, which is highly limited under high pressure.

In the view of published work within the subject of annealing under the high hydrostatic pressure, it seems that annealing under high hydrostatic pressure can be an effective way to control the grain growth in nanostructured materials and produce fine grain materials which could not be obtained under atmospheric pressure due to fast and uncontrollable grain growth. However, this requires full understanding of processes taking place during annealing under high hydrostatic pressure. Therefore, the aim of the current study was to investigate the influence of high pressure on the recrystallization and grain growth of a nanostructured stainless steel 316LVM. To this end, specimens of an austenitic stainless steel were deformed by profile rolling (PR)—a conventional deformation technique, and by high-pressure torsion (HPT) - an SPD technique; the samples were then annealed under a pressure of 2 and $6 \mathrm{GPa}$ and, for comparison, under atmospheric pressure. The HPT process was chosen because it is one of the most efficient SPD processes for grain refinement [28-33]. 


\section{Materials and methods}

Sandvik Bioline 316LVM austenitic stainless steel was used; this is a low-carbon, vacuum-melted $316 \mathrm{~L}$ grade stainless steel, UNS S31673 certified to ASTM F138, supplied as annealed in the form of 50-mmdiameter rods, possessing the chemical composition shown in Table 1.

The samples were conventionally deformed using profile rolling (PR) with a reduction in cross section of 23.8, which corresponds to a strain value of approximately 3.4. In this case, the strain was calculated according to the equation $\varepsilon=2 \ln \left(d_{1} / d_{2}\right)$, where $d_{1}(\phi=12 \mathrm{~mm})$ is the initial diameter and $d_{2}(\phi=$ $2.2 \mathrm{~mm}$ ) the final diameter. It must be pointed out that this calculation is only an approximation, since the cross section is not actually a circle. Additionally, the material was cut into disks with a diameter of $10 \mathrm{~mm}$ and a thickness of $0.8 \mathrm{~mm}$. The disks were processed at room temperature using an HPT device at a constant pressure of $6.0 \mathrm{GPa}$. The disks were torsionally strained to 5 revolutions. The strain was well defined as simple shear, $\gamma$, and was calculated according to the equation $\gamma=2 \pi \times r \times n / t$, where $r$, $n$ and $t$ are the distance from the torsion axes, the number of applied revolutions and the mean thickness of the sample, respectively. The equivalent strains $\varepsilon$ eq $=\gamma / \sqrt{3}$ calculated $3.5 \mathrm{~mm}$ from the central point of the sample after 5 revolutions were equal to 79. A phase analysis of the as-received, HPT- and PR-processed samples was performed on a Bruker D8 Advance diffractometer with nickel-filtered copper radiation $(\lambda=0.154056 \mathrm{~nm})$. The data were collected in a range between $10^{\circ}$ and $120^{\circ} 2 \Theta$, with a step width of $\Delta 2 \Theta=0.02^{\circ}$ and a counting time $5 \mathrm{~s}$. The energy of the emitter beam was $40 \mathrm{kV}$, and the current was $40 \mathrm{~mA}$.

After PR, samples of $3 \mathrm{~mm}$ in height were cut from a $500 \mathrm{~mm}$ rod. After the HPT experiments, disks of $5 \mathrm{~mm}$ in diameter were cut in such a way that the radius of the sample after HPT became the diameter

Table 1 Chemical composition (wt $\%$ ) of austenitic stainless steel 316LVM

\begin{tabular}{llllllllll}
\hline $\mathrm{C}$ & $\mathrm{Si}$ & $\mathrm{Mn}$ & $\mathrm{P}$ & $\mathrm{S}$ & $\mathrm{Cr}$ & $\mathrm{Ni}$ & $\mathrm{Mo}$ & $\mathrm{Cu}$ & $\mathrm{N}$ \\
\hline 0.025 & 0.6 & 1.7 & 0.025 & 0.003 & 17.5 & 13.5 & 2.8 & 0.1 & $<0.1$ \\
\hline
\end{tabular}

of the sample for the annealing experiments. The dimensions of the samples were limited by the dimensions of the toroidal high-pressure cell. The samples were annealed at $900{ }^{\circ} \mathrm{C}$ for $10 \mathrm{~min}$, either at atmospheric pressure $(0.1 \mathrm{MPa})$ or at a hydrostatic pressure of 2 or $6 \mathrm{GPa}$ and. To verify whether annealing under high hydrostatic pressure leads to the creation of similar microstructures as conventional annealing for a shorter time, additional experiments of annealing under $0.1 \mathrm{MPa}$ for $4 \mathrm{~min}$ were performed. A toroidal high-pressure cell $[34,35]$ was used for the high-pressure annealing, and a conventional furnace for annealing at atmospheric pressure. Further on in this text, these samples will be referred to as PR_10_0.1 MPa, PR_10_2GPa, PR_10_6GPa, PR_4_0.1 $\mathrm{MPa}$, HPT_10_0.1 MPa, HPT_10_2GPa, HPT_10_6GPa and HPT_4_0.1 MPa.

The microstructure of the samples was investigated using a Hitachi SU 8000 scanning electron microscope working at $5 \mathrm{kV}$ in the BSE mode and a JEOL JEM 1200 EX transmission electron microscope working at $120 \mathrm{kV}$. For the scanning electron microscopy examination, the samples were prepared by electropolishing using Struers electrolyte A3. The parameters for electropolishing were as follows: voltage $-15 \mathrm{~V}$, time $-15 \mathrm{~s}$. For the transmission electron microscopy examination, the samples were prepared by mechanical polishing to a disk thickness of about $100 \mu \mathrm{m}$. Further thinning to reach a thickness appropriate for electron transparency was carried out by electropolishing using Struers electrolyte A2. In the case of the PR samples, the microstructure was analyzed in the center of the samples. In the case of the HPT samples, for microstructure analysis of the cross sections, disks with a diameter of $3 \mathrm{~mm}$ were cut from the edge regions of each disk so that the areas of observation were $3.5 \mathrm{~mm}$ from the central point. Further thinning was carried out by means of a conventional procedure. Qualitative and quantitative studies as well as the percentage share of the recrystallized areas of the microstructures were conducted using stereological and image analysis methods [36, 37]. The grain size was determined as the equivalent diameter, $d_{2}$, defined as the diameter of a circle having an area equal to the surface area of a given grain. The grain shape was described by grain elongation factor, defined as the ratio of the maximum to the equivalent diameter $d_{\max } / d_{2}$. To establish the variation of the size of individual grains, a variation coefficient, $\mathrm{CV}\left(d_{2}\right)$, defined as the ratio of the 
standard deviation SD $\left(d_{2}\right)$ to the mean value, was determined.

Microhardness measurements were conducted on polished cross sections of the PR and HPT samples. These measurements were made using a Zwick microhardness tester under a load of $200 \mathrm{~g}$. The values of the Vickers microhardness, Hv, were recorded along a diameter of the PR and HPT samples with a separation of $0.1 \mathrm{~mm}$.

\section{Results}

\section{X-ray diffraction analysis}

Figure 1 shows $\mathrm{X}$-ray diffraction profiles of the asreceived, PR- and HPT-processed samples. The X-ray diffraction profiles reveal a $\gamma$-austenite phase (fcc) without any evidence of $\varepsilon$-martensite (hcp) or $\alpha^{\prime}$ martensite (bcc). The greatest broadening of peaks is observed for the HPT sample and is a result of microstructure refinement and microstrains.

\section{Microhardness measurements}

Microhardness measurements on cross sections of the PR- and HPT-processed samples after annealing at $900{ }^{\circ} \mathrm{C}$ under various pressures for 4 and $10 \mathrm{~min}$ are presented in Fig. 2. After HPT, the microhardness reaches an average value of $471 \mathrm{Hv} 0.2$, which is higher by 46 units than after PR. Moreover, the HPT causes a more homogeneous distribution of microhardness on the diameter since the standard

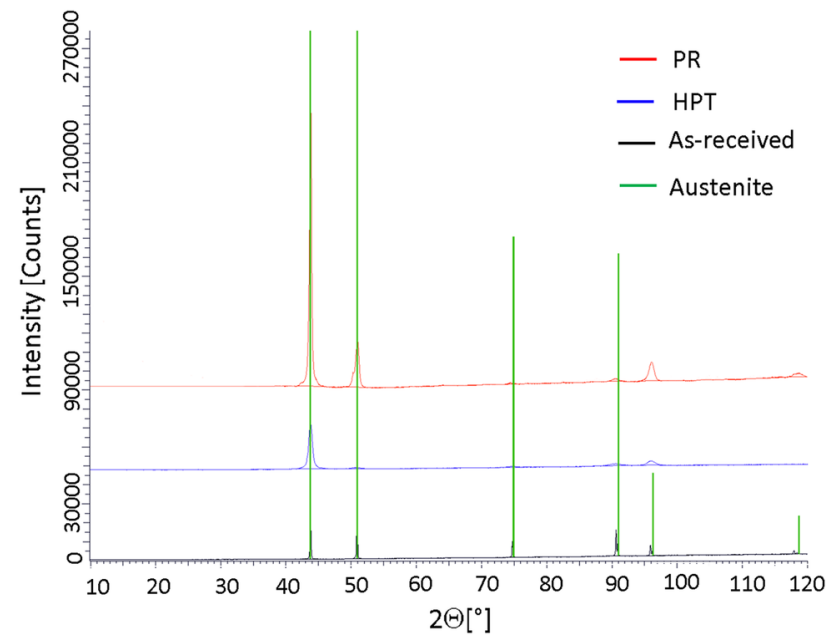

Figure 1 X-ray diffraction profiles of as-received, PR-, and HPTprocessed samples.
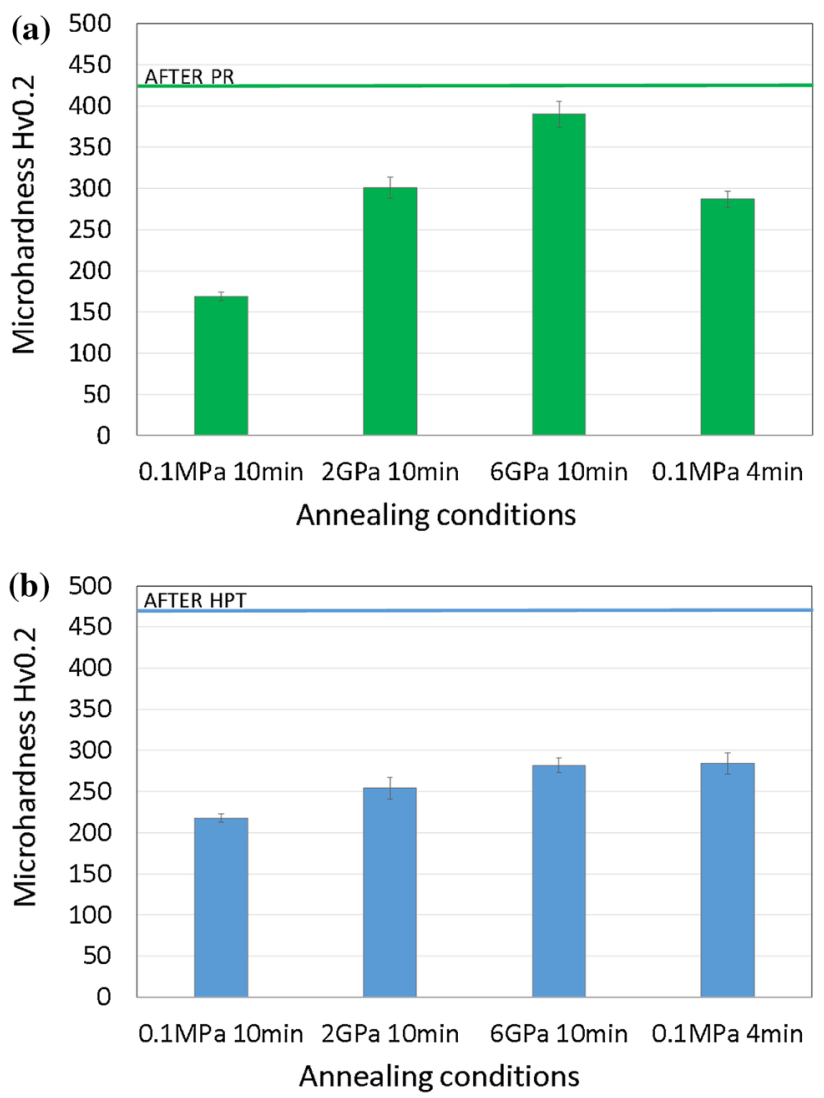

Figure 2 Microhardness Hv0.2 of PR- a and HPT-processed b austenitic stainless steel annealed under $0.1 \mathrm{MPa}$ and 2 and $6 \mathrm{GPa}$ at $900{ }^{\circ} \mathrm{C}$ for $10 \mathrm{~min}$ and additionally for $4 \mathrm{~min}$ under $0.1 \mathrm{MPa}$.

deviation equals $14 \mathrm{Hv} 0.2$, whereas after PR it is twice as high (it must be pointed out that the diameter of the HPT sample is two times greater than that after PR). Annealing under high hydrostatic pressure has a considerable impact on the microhardness values of HPT- and PR-processed samples. There is a tendency for both samples that the higher the pressure during annealing, the higher the microhardness value retained. However, the PR samples showed greater microhardness values for annealing under a pressure of 2 and $6 \mathrm{GPa}$ (301 and $390 \mathrm{Hv} 0.2$, respectively) than the HPT samples (254 and $282 \mathrm{Hv} 0.2$, respectively). Additionally, annealing was performed for $4 \mathrm{~min}$ at $0.1 \mathrm{MPa}$. In the case of the PR samples, the microhardness value after annealing for $4 \mathrm{~min}$ can be compared with that obtained for annealing under $2 \mathrm{GPa}$ for $10 \mathrm{~min}$ (287 and $301 \mathrm{Hv} 0.2$, respectively). In the case of the HPT samples, annealing for $4 \mathrm{~min}$ at $0.1 \mathrm{MPa}$ causes changes in the microhardness similar to annealing under 6 GPa (282 and 284 Hv0.2, respectively). 


\section{Microstructure observation}

\section{Microstructure observation after plastic deformation}

The microstructure of the cross sections is severely refined in both the PR- and HPT-processed samples, as presented in Fig. 3. The microstructure observations are supported by the selected area diffraction (SAED) patterns from an area having a diameter of approximately $4 \mu \mathrm{m}$. The presence of diffraction rings in the SAED confirms that the microstructure has been refined. However, the non-uniform intensity of the rings in the SAED of the PR sample indicates that the microstructure is more textured after PR than after HPT. Moreover, the SAED patterns indicate that the PR- and HPT-processed samples consist of an $\gamma$ austenite phase. In the case of the HPT-processed sample, one can notice, apart from the $\gamma$-austenite phase (fcc), a weak ring from $\varepsilon$-martensite phase (hcp). Some authors suggest that $\varepsilon$-martensite is not a perfect hcp structure, but consider it as a heavily faulted fcc $\gamma$-austenite structure with a special arrangement of stacking faults [38]. The presence of an $\varepsilon$-martensite phase was not revealed in the X-ray analysis, probably due to the small volume of this phase beyond the detection threshold.

Microscopy observations at greater magnifications reveal that the microstructures of the PR and HPT samples differ considerably. The microstructure of the PR sample in cross section is non-homogeneous. It consists of elongated deformation bands divided into subgrains of thickness in the range of $50-100 \mathrm{~nm}$ and length of $100-300 \mathrm{~nm}$, and deformation nanotwins of thickness of $5-10 \mathrm{~nm}$, as shown in detail in Fig. 4. In the case of the HPT sample, in cross section the microstructure has been transformed into small fragments forming nanocrystallites. The average grain size is below $100 \mathrm{~nm}$. Inside some grains, one can notice a high density of dislocations (Fig. 5). It was also observed that the longest grain axis is oriented parallel to the HPT shear plane. However, as this has been the subject of previous research, this issue will not be further explored here [39, 40]. (a)
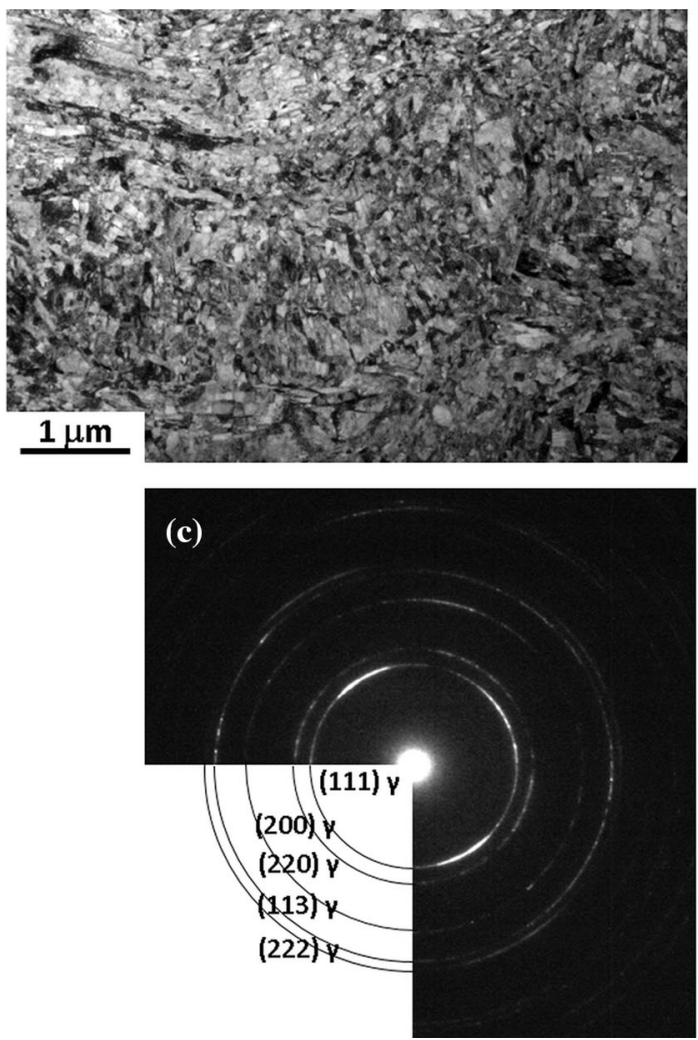

(b)
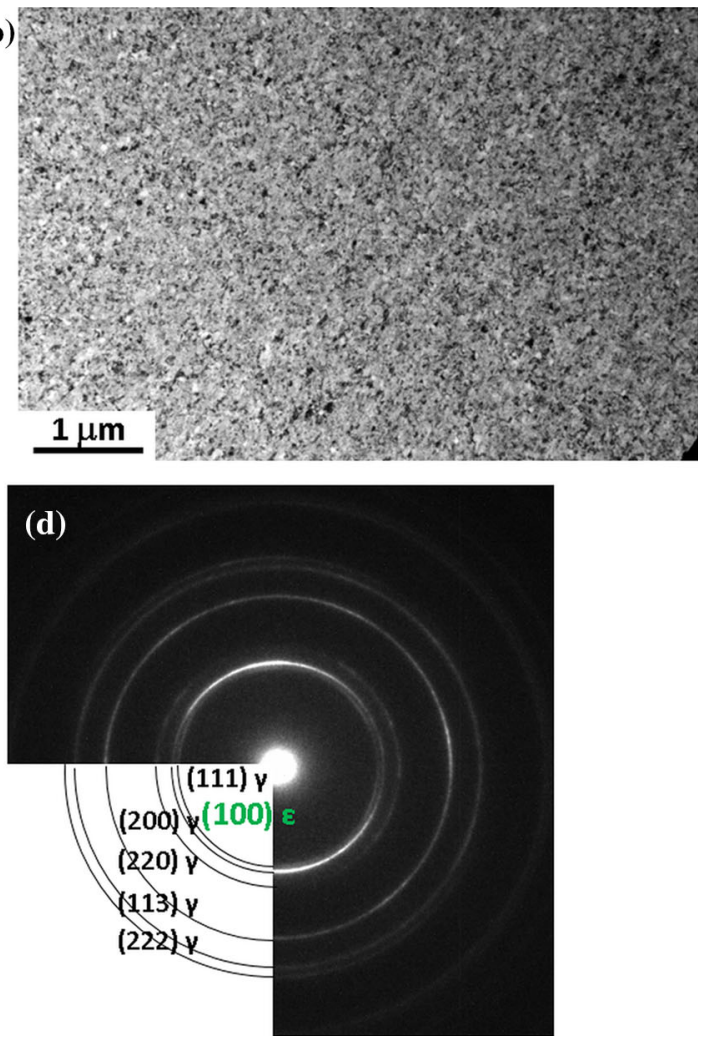

Figure 3 Microstructures of the a PR- and b HPT-processed samples - cross sections, SAED patterns of $\mathbf{c}$ PR- and d HPT-processed samples. 
(a)

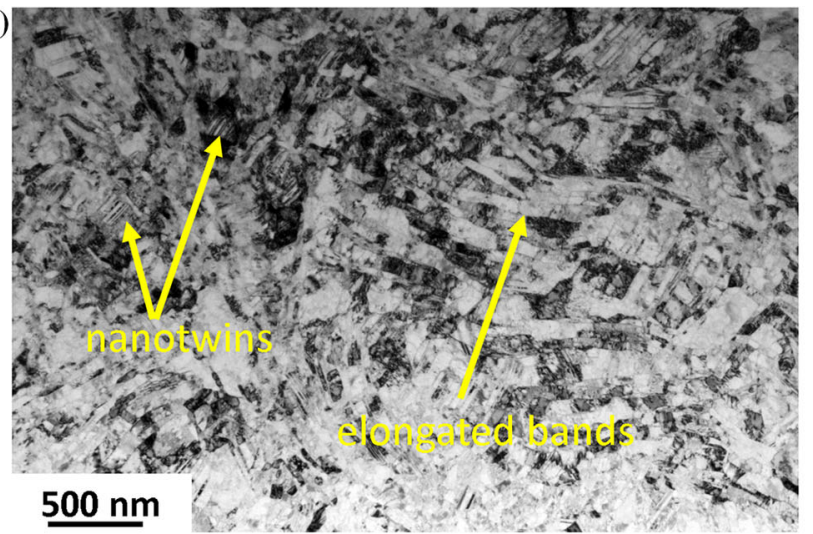

(c)

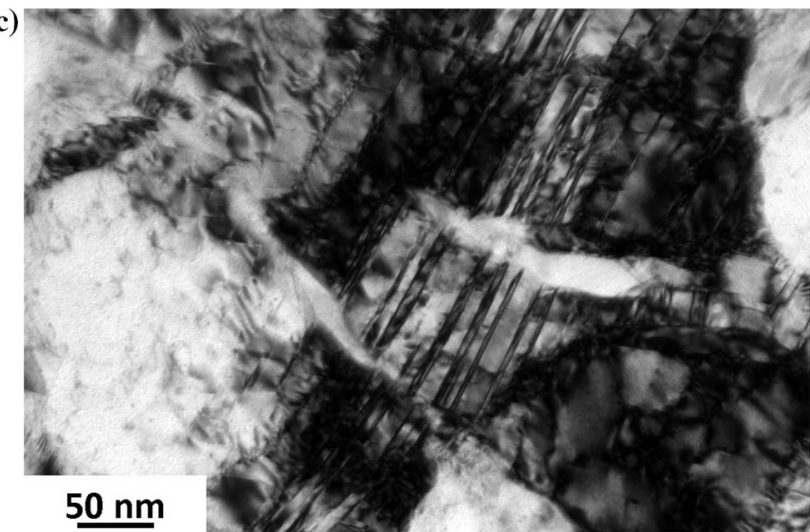

(e)

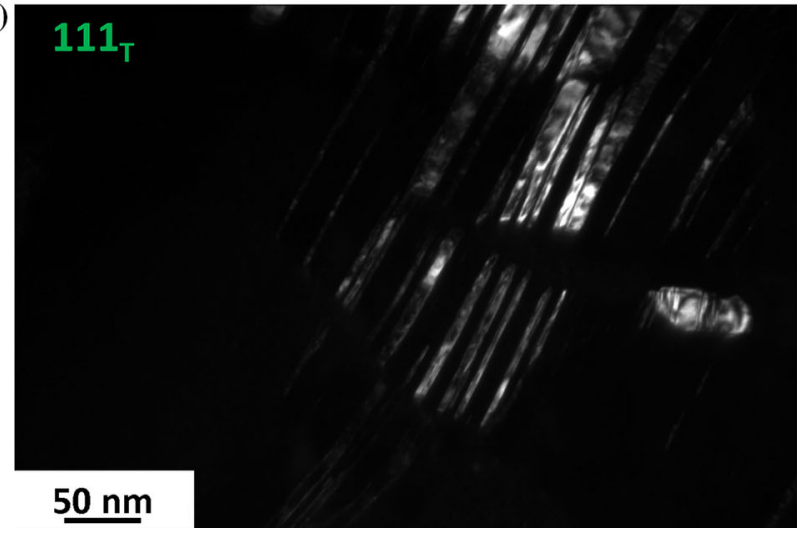

Figure 4 Microstructures of the PR-processed sample-cross section: a global view, b deformation bands, c deformation nanotwins in the bright field, $\mathbf{d}$ SAED pattern from nanotwinned

\section{Microstructure observations after annealing}

The microstructures of the PR samples and HPT samples after annealing at $900{ }^{\circ} \mathrm{C}$ under $0.1 \mathrm{MPa}, 2$ and $6 \mathrm{GPa}$ for $10 \mathrm{~min}$ are shown in Fig. 6 (in BSE mode SEM) and Fig. 7 (TEM). The average equivalent diameter $d_{2}$, standard deviation SD $\left(d_{2}\right)$ and coefficient of variation $\mathrm{CV}\left(d_{2}\right)$ of grains are presented in the form of charts in Fig. 7. An analysis of the

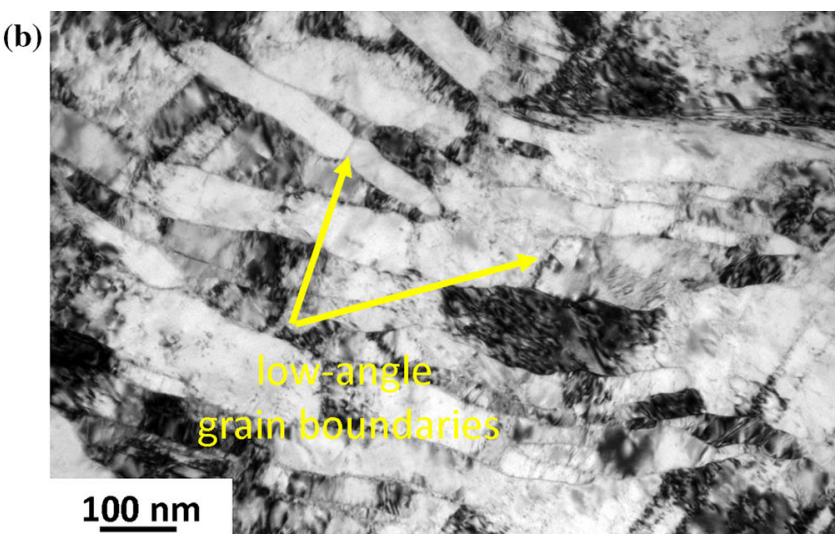

(d)

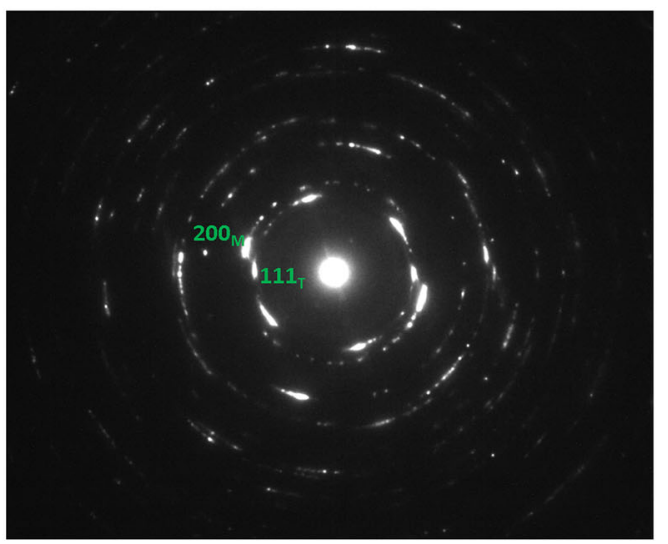

(f)

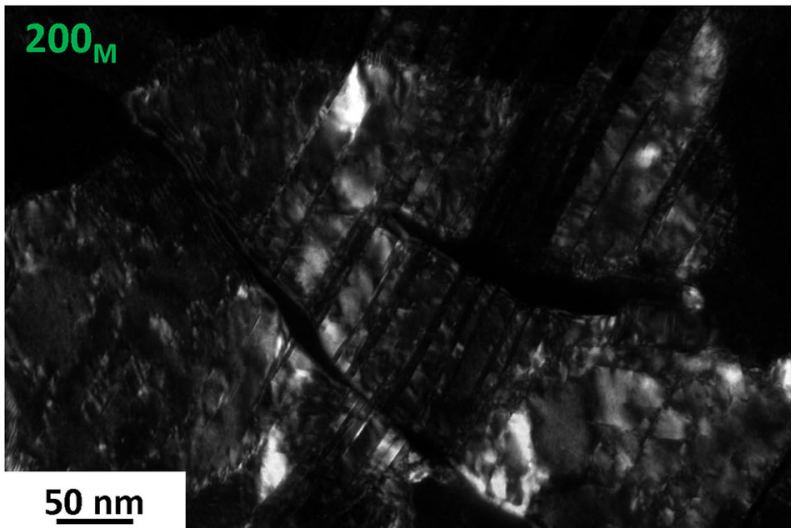

area of $0.6 \mu \mathrm{m}$ in diameter, e deformation nanotwins in the dark field, $\mathbf{f}$ matrix in the dark field.

microstructures of HPT_10_0.1 $\mathrm{MPa}$ and PR_10_0.1 MPa leads to the conclusion that the samples are fully recrystallized. The average equivalent diameter is greater for the PR_10_0.1 MPa than for the HPT_10_0.1 MPa (4.3 and $2.0 \mu \mathrm{m}$, respectively). Furthermore, the microstructure elongation factor values are comparable (1.35 and 1.28, respectively, for PR_10_0.1 MPa and HPT_10_0.1 MPa), which indicates fully equiaxial grain structure. 
(a)

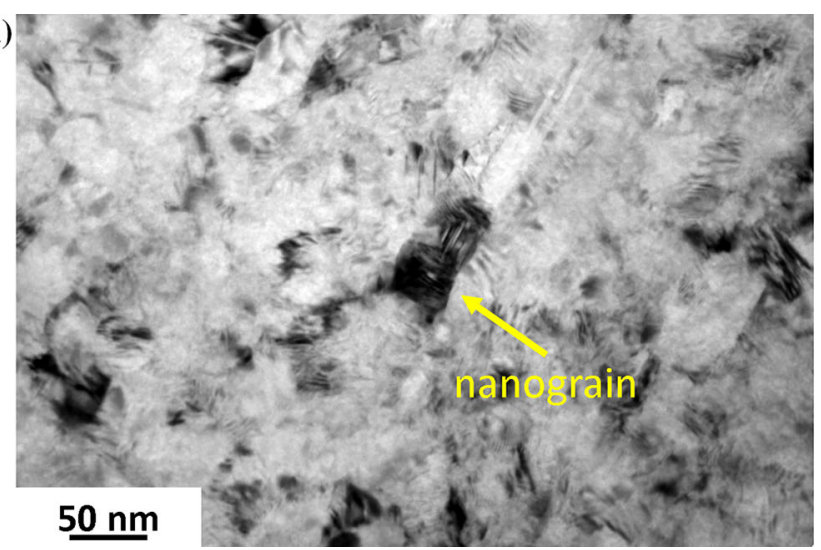

(b)

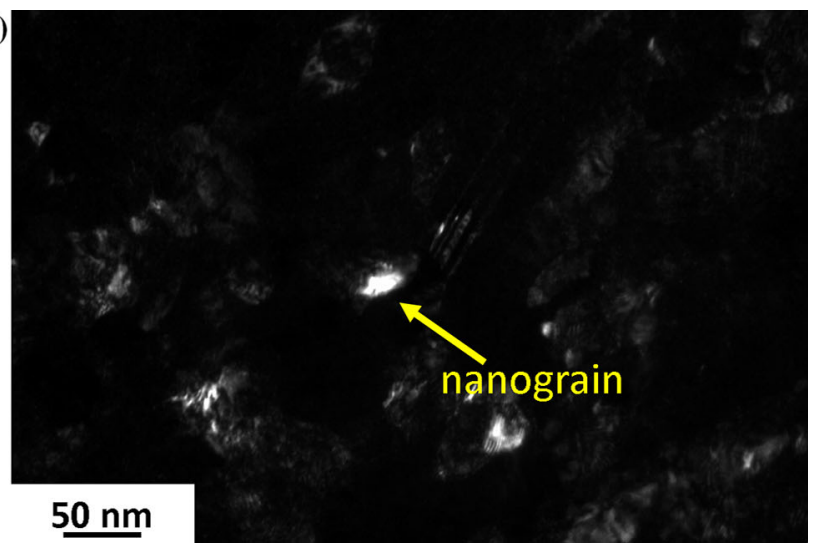

Figure 5 Microstructures of the HPT-processed sample- $\mathbf{a}$ in the bright field, $\mathbf{b}$ in the dark field, obtained by selecting a part of a diffraction ring from the (111) planes.
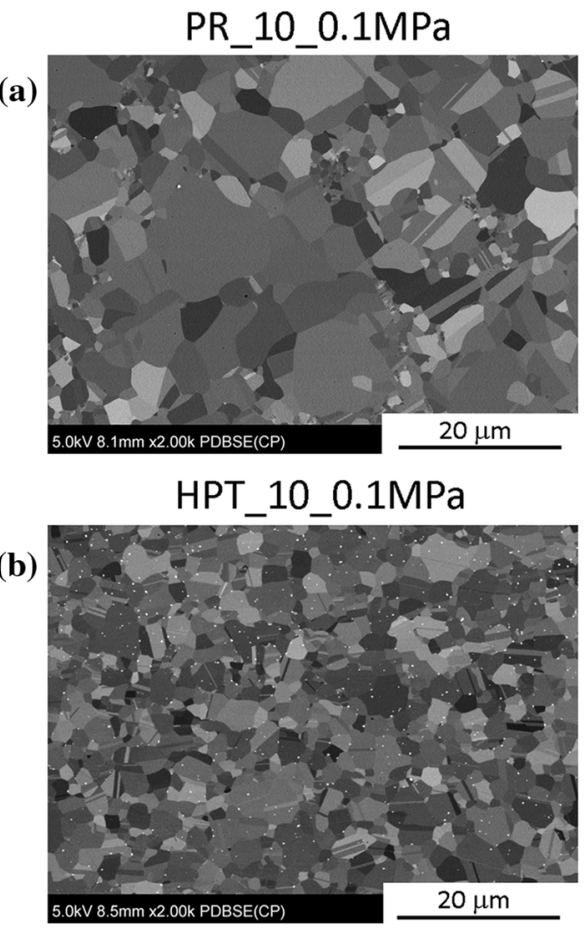

PR_4_0.1MPa

(c)

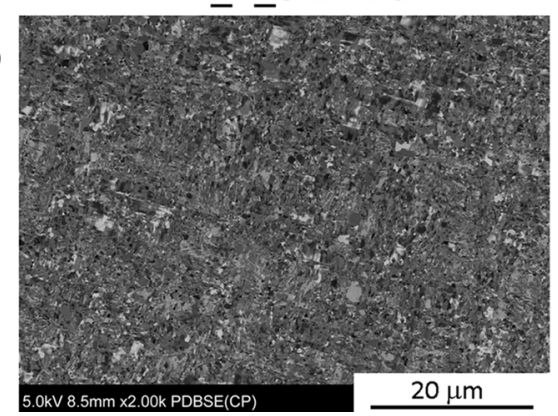

Figure 6 a Microstructures of PR-processed samples after annealing at $900{ }^{\circ} \mathrm{C}$ for $10 \mathrm{~min}$ under $0.1 \mathrm{MPa}, 2 \mathrm{GPa}$ and $6 \mathrm{GPa}$; b microstructures of HPT-processed samples after annealing at
PR_10_2GPa
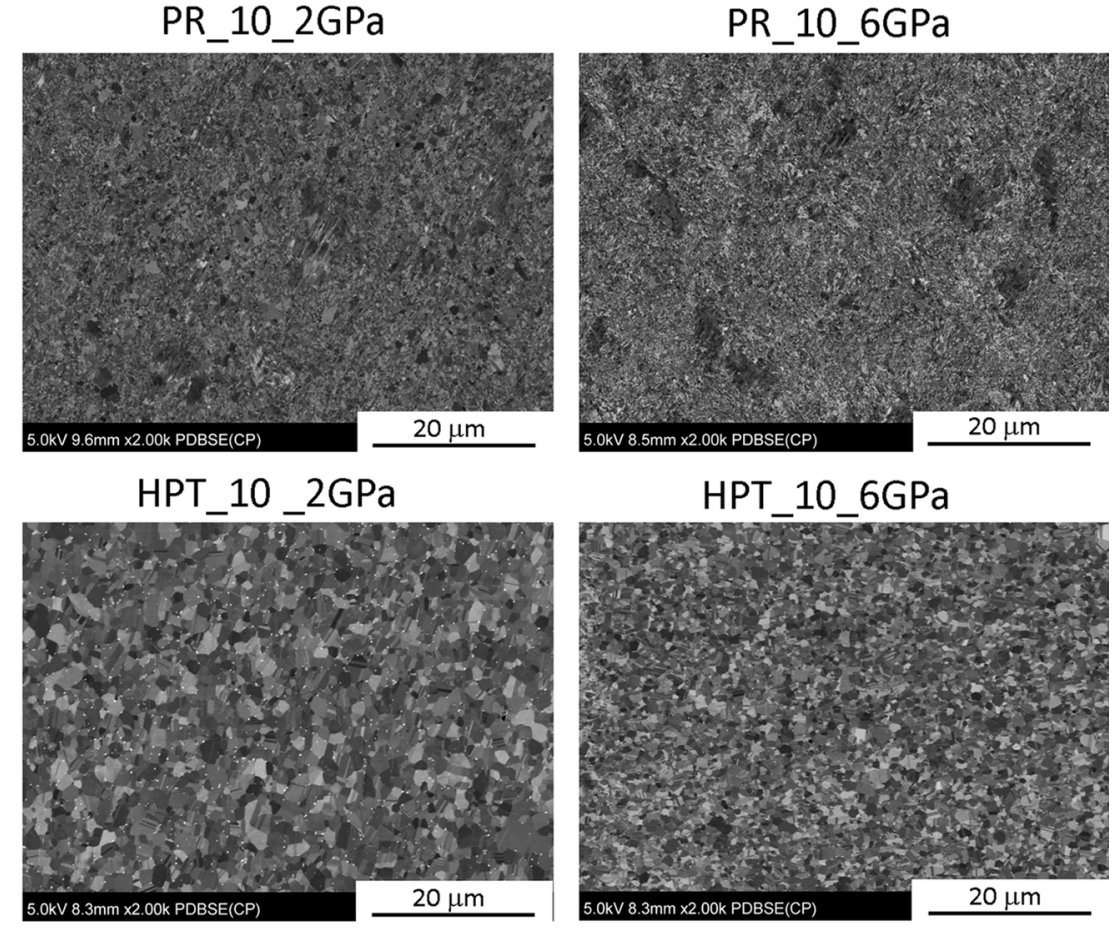

HPT_4_0.1MPa

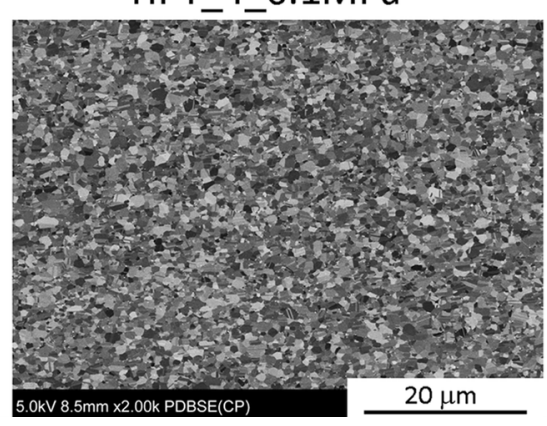

$900{ }^{\circ} \mathrm{C}$ for 10 min under $0.1 \mathrm{MPa}, 2$ and $6 \mathrm{GPa}$; microstructures of PR- and HPT-processed samples after annealing at $900{ }^{\circ} \mathrm{C}$ for 4 min under 0.1 MPa; SEM in BSE mode. 

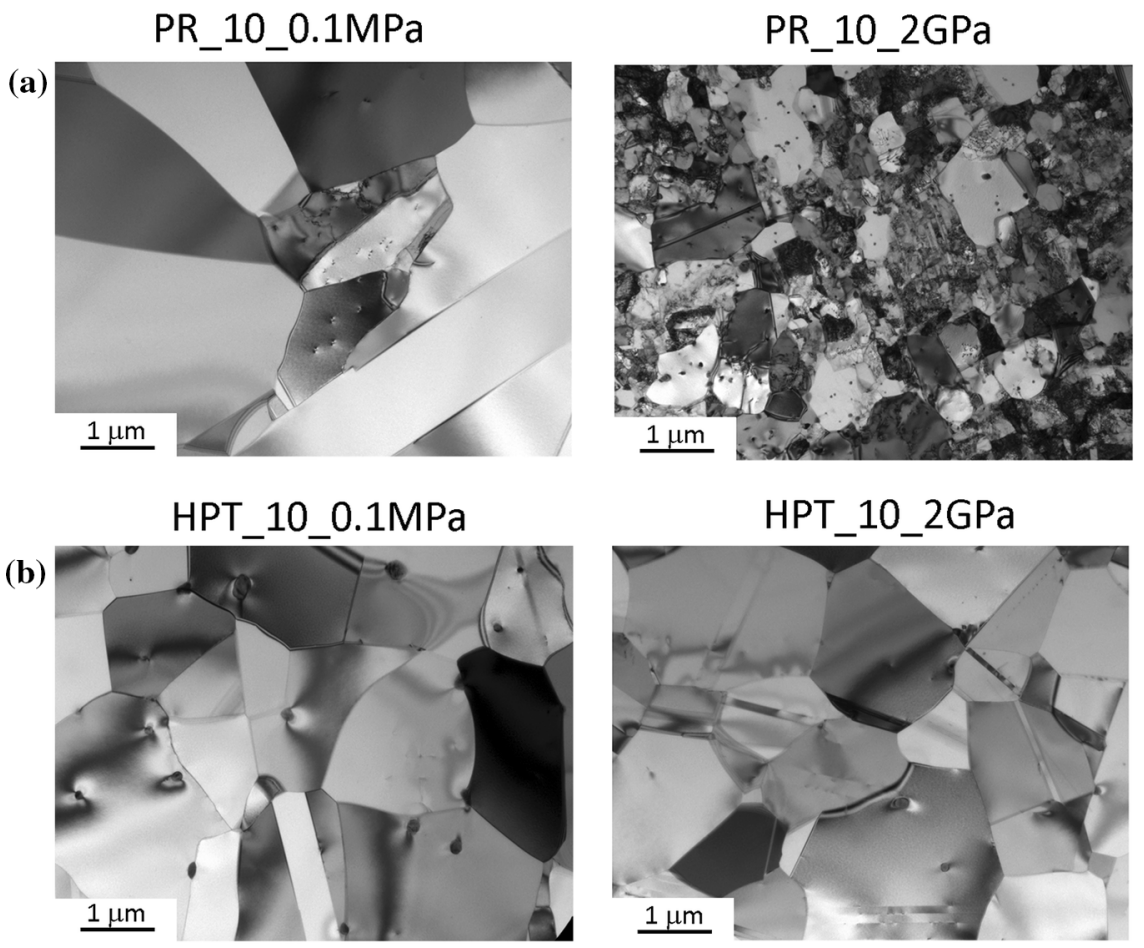
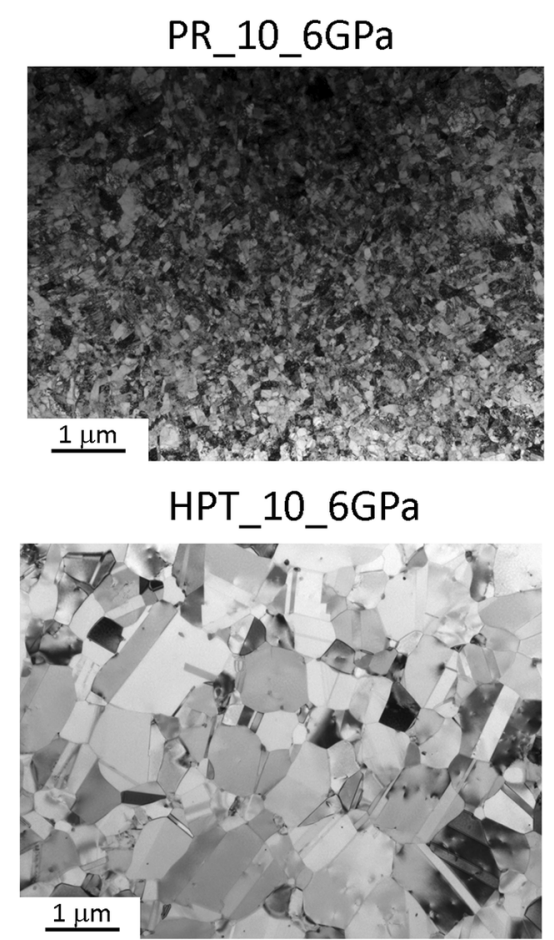

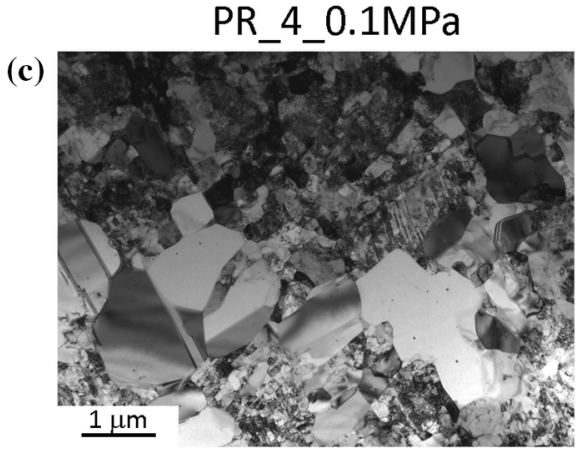

Figure 7 a Microstructures of PR-processed samples after annealing at $900{ }^{\circ} \mathrm{C}$ for $10 \mathrm{~min}$ under $0.1 \mathrm{MPa}, 2$ and $6 \mathrm{GPa}$; b microstructures of HPT-processed samples after annealing at

Nevertheless, they differ in the value of the coefficient of variation, which is significantly higher for the PR_10_0.1 MPa (0.79) than for the HPT_10_0.1 MPa (0.47). This implies that the distribution of the equivalent diameter in the PR_10_0.1 MPa is wider than in the HPT_10_0.1 MPa. The smaller grains in the PR_10_0.1 MPa contain some dislocations, whereas the HPT_10_0.1 MPa contains grains free from dislocations.

Applied annealing pressure at $900{ }^{\circ} \mathrm{C}$ hinders recrystallization and grain growth in the PR-processed samples and grain growth in the HPT-processed samples. In the case of the PR samples, the equivalent diameter reaches $0.42 \mu \mathrm{m}$ under $2 \mathrm{GPa}$

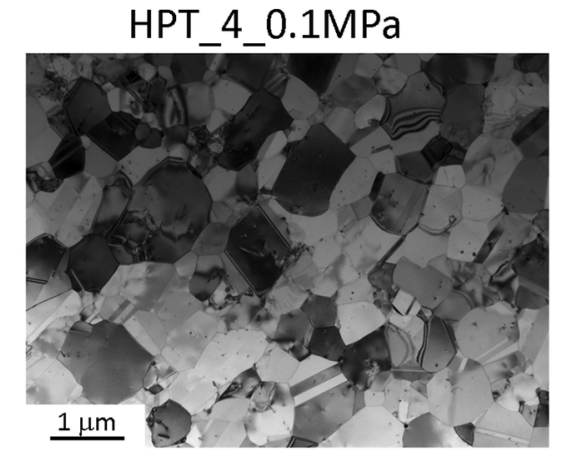

$900{ }^{\circ} \mathrm{C}$ for 10 min under $0.1 \mathrm{MPa}, 2$ and $6 \mathrm{GPa}$; $\mathrm{c}$ microstructures of PR- and HPT-processed samples after annealing at $900{ }^{\circ} \mathrm{C}$ for 4 min under $0.1 \mathrm{MPa}$; TEM.

and only $0.087 \mu \mathrm{m}$ under $6 \mathrm{GPa}$. Between the recrystallized areas, one can notice areas where there has been no recrystallization. In the case of the HPT samples, the equivalent diameter reaches $1.35 \mu \mathrm{m}$ under $2 \mathrm{GPa}$ and $0.58 \mu \mathrm{m}$ under $6 \mathrm{GPa}$, which is greater than in the PR samples. Moreover, in contrast to the PR samples, there are no non-recrystallized areas between the recrystallized grains. As well as investigating the effect of high hydrostatic pressure on the equivalent diameter of the PR and HPT samples, attention was paid to the impact of high hydrostatic pressure on the elongation parameter and coefficient of variation. It seems that the high hydrostatic pressure applied had no impact on the 
elongation parameter, which was approximately 1.3 for all annealing conditions for both the PR and HPT samples. Nevertheless, the pressure applied during annealing had a significant impact on the coefficient of variation. There are two tendencies visible. In the case of the PR samples, the coefficient of variation decreases with an increase of pressure from 0.79 under $0.1 \mathrm{MPa}$ to 0.46 under $6 \mathrm{GPa}$, whereas in the case of the HPT samples it increases from 0.47 under $0.1 \mathrm{MPa}$ to 0.64 under $6 \mathrm{GPa}$. It means that the abnormal grain growth, represented by a high coefficient of variation, is favorized in the PR sample under the atmospheric pressure and in the HPT sample under the increased pressure.

To verify whether annealing under high hydrostatic pressure leads to the creation of similar microstructures as does conventional annealing, but over a shorter time, additional experiments of annealing under $0.1 \mathrm{MPa}$ were performed. The microstructures obtained are presented in Figs. 6 and 7. The average equivalent diameter $d_{2}$, standard deviation SD $\left(d_{2}\right)$ and coefficient of variation $\mathrm{CV}\left(d_{2}\right)$ of the grains are presented in Fig. 8. This experiment makes it possible to observe that the retardation of annealing induced by annealing at $2 \mathrm{GPa}$ for $10 \mathrm{~min}$ in the case of the PR samples can be compared with annealing for 4 min under $0.1 \mathrm{MPa}\left(d_{2}=0.42, d_{\max } /\right.$ $d_{2}=1.31, \mathrm{CV}\left(d_{2}\right)=0.78$-for PR_10_2 GPa, $d_{2}=0.44$, $d_{\max } / d_{2}=1.39, \mathrm{CV}\left(d_{2}\right)=0.74$-for PR_4_0.1 MPa). In the case of the HPT samples, 4-min annealing at $0.1 \mathrm{MPa}$ causes similar changes in the microstructure as annealing at $6 \mathrm{GPa}$ for $10 \mathrm{~min}\left(d_{2}=0.58, d_{\max } /\right.$ $d_{2}=1.31, \quad C V\left(d_{2}\right)=0.64$-for HPT_10_6 GPa, $d_{2}=0.55, \quad d_{\max } / d_{2}=1.33, \quad \mathrm{CV}\left(d_{2}\right)=0.54$-for HPT_4_0.1 MPa). One difference in the microstructure between HPT_10_6GPa and HPT_4_0.1 MPa lies in the value of the coefficient of variation, which is significantly higher for annealing at $6 \mathrm{GPa}$ than at $0.1 \mathrm{MPa}$.

\section{Discussion}

\section{Comparison of the thermal stability of HPT- and PR-processed samples under 0.1 MPa}

Even though the TEM observations confirmed the refinement of the microstructures of the HPT- and PR-processed samples, their behavior during annealing under $0.1 \mathrm{MPa}$ was different. The differences are visible after annealing for 4 and $10 \mathrm{~min}$. After $4 \mathrm{~min}$ of annealing, it can be noticed that in the PR-processed samples discontinuous recrystallization occurred, whereas in the HPT-processed samples the recrystallization was continuous. This discontinuous recrystallization (frequently called primary recrystallization) is the result of an inhomogeneous microstructure produced during deformation. If the microstructure after deformation is inhomogeneous, which is true for low-to-moderate strains (in the case of the PR-processed samples $-\varepsilon=3.4$ ) during deformation, it means that there are preferred sites for the formation of nuclei having high local misorientations, e.g., highly misoriented regions within deformation bands [41]. The process of heterogeneous nucleation leads, over a longer annealing time, to a microstructure that is fully recrystallized but of diversified grain size. In the case of the austenitic stainless steel, continuous recrystallization was reported for a total strain of 6.4 reached during multi-axial compression [42]. During annealing of the HPT-processed sample that was deformed to a high strain of 79 , the strain-induced high-angle grain boundaries change to conventional ones. As a result, homogeneous nucleation and, for longer times, normal grain growth were perceived. This kind of behavior has been previously observed in austenitic stainless steels deformed by HPT and subsequently annealed [43].

Moreover, after $10 \mathrm{~min}$ of annealing, the HPTprocessed samples showed smaller grain size than the PR-processed samples. The visibly enhanced thermal stability here may be explained by the fact that, during heating, the recovery of the non-equilibrium grain boundary structure (definitely present in a higher volume in the HPT-processed samples than in the PR-processed samples) proceeds quite rapidly due to their high diffusivity [44]. Non-equilibrium grain boundaries are specific grain boundaries that possess an increased free energy density, increased width, a high density of dislocations associated with the near-boundary region, and correspondingly large residual microstrains [8]. This leads to a rapid decrease in the driving force of the grain growth. Another important factor explaining the enhanced thermal stability of a HPT sample is the more uniform microstructure after deformation in the case of HPT than in a PR-processed sample. The impact of the uniform microstructure on the thermal stability was proven in the experiment on 

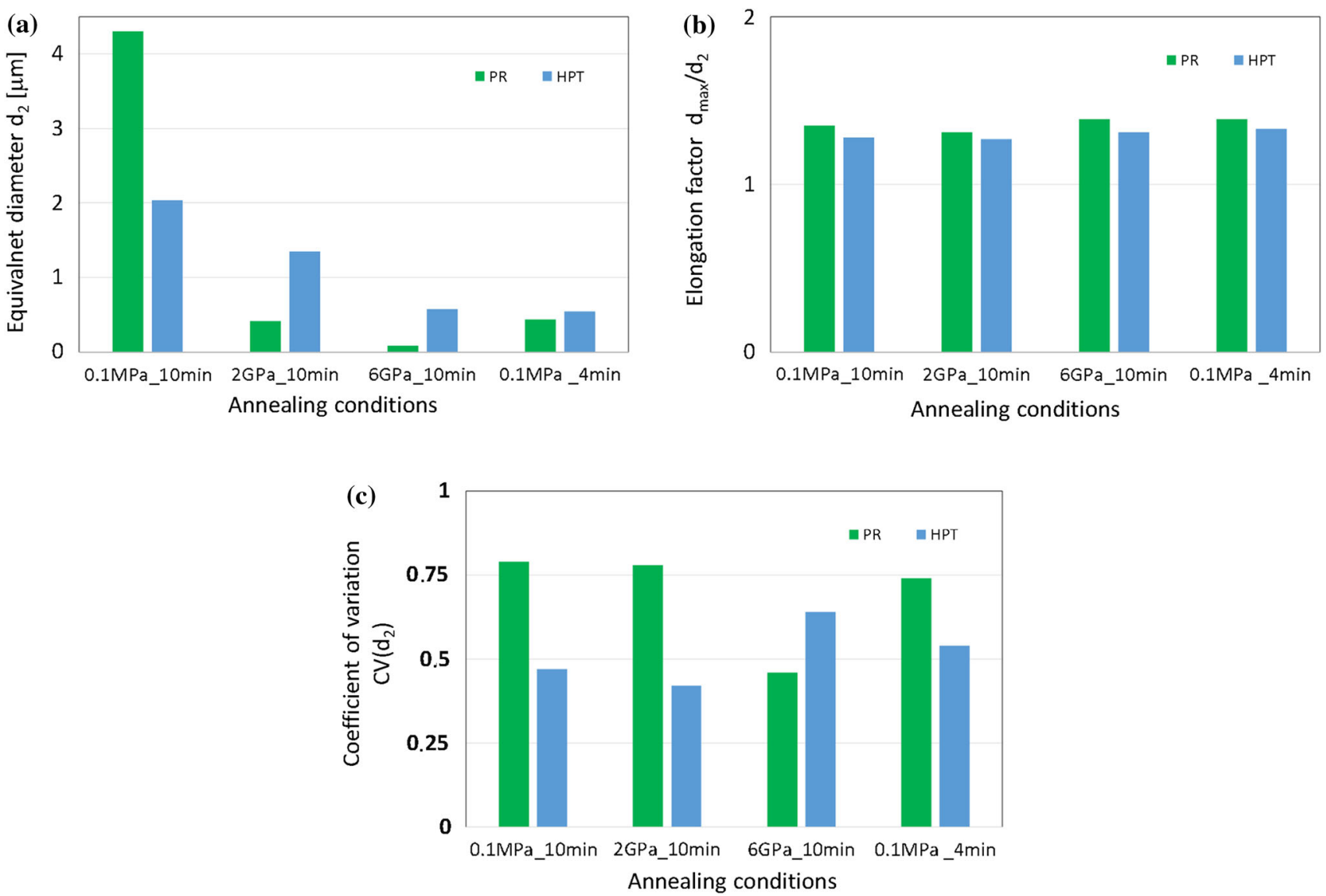

Figure 8 a Average equivalent diameter $d_{2}$, b elongation factor $d_{\max } / d_{2}$, and $\mathbf{c}$ coefficient of variation CV $\left(d_{2}\right)$ of grains in PR- and HPTprocessed samples after annealing at $900{ }^{\circ} \mathrm{C}$ for 10 min under $0.1 \mathrm{MPa}, 2$ and $6 \mathrm{GPa}$ and for 4 min under $0.1 \mathrm{MPa}$.

molybdenum [9]. The thermal stability of molybdenum processed by HPT exceeded significantly the respective one for multi-step forging despite the lower deformation degree in the latter case, which was related to the more homogeneous grain size distribution in the former case. As a result, the mobility of grain boundaries decreases, which results in their enhanced thermostability.

\section{Impact of high hydrostatic pressure on recrystallization and grain growth in nanostructured austenitic steel 316LVM}

The above results indicate that hydrostatic pressures of 2 and $6 \mathrm{GPa}$ have a considerable impact on the process of recrystallization and grain growth in the PR samples and mainly on grain growth in the HPT samples. The fact that increasing the annealing pressure retards recrystallization and grain growth has been investigated in the past in numerous studies [20-27]. For example, in one such early study, it was found that a pressure of $4.2 \mathrm{GPa}$ applied while annealing polycrystalline copper cold-rolled to $98 \%$ retarded both the initiation and the rate of recrystallization [20]. In another work, it was proved that that grain growth decreased by a factor of 1.3 under a high pressure of 1.2 GPa in aluminum rolled to a $90 \%$ reduction [26]. A similar effect of recrystallization retardation was observed during annealing at $300{ }^{\circ} \mathrm{C}$ of an $\mathrm{Al}-2 \% \mathrm{Mg}$ alloy under an applied stress of $10 \mathrm{MPa}$ [45].

In the present study, one fact that requires some explanation is the considerable difference in the retardation of the rate of recrystallization and grain growth between the PR- and HPT-processed samples. Such an explanation must take into consideration the different nature of the grain boundaries in the PRand HPT-processed samples, despite the fact that both samples possess highly refined microstructures.

1. Firstly, in the PR-processed samples, most of the microstructure is occupied by nanotwins and 
elongated deformation bands consisting of subgrains, whereas in the HPT-processed samples there is a preponderance of nanograins. In previous studies on micrograined materials, it was explained that low-angle grain boundaries, present in the PR samples, move by the vacancy diffusion mechanism [26]. However, the vacancy concentration in the material decreases with increasing pressure during annealing [26]. For this reason, the movement of low-angle grain boundaries is strongly slowed down during annealing under high hydrostatic pressure. This explains the fact that there are non-recrystallized areas in the PR-processed samples after annealing under high hydrostatic pressure. Moreover, in the PR samples there is a high density of nanotwin boundaries viewed as $60^{\circ}<111>$ twist boundaries or $70.5^{\circ}<110>$ tilt boundaries. It is known that $<110>$ tilt boundaries move by some cooperative motion of several atoms, while $<100>$ and $<111>$ tilt boundaries move by a single atom mechanism, which can be achieved more easily under high hydrostatic pressure [21, 22]. This fact also explains the retardation of recrystallization under high hydrostatic pressure in the PR-processed samples. A strong retardation of grain growth was also observed in a nanotwinned austenitic stainless steel refined by HE after annealing for $10 \mathrm{~min}$ under a pressure of $6 \mathrm{GPa}\left(d_{2}=133 \mathrm{~nm}\right)$. The behavior of HE-processed and PR-processed samples during annealing under high hydrostatic pressure confirms that the migration of twins boundaries is hampered under high pressure.

2. Secondly, these samples differ in the equivalent strain applied during deformation, which was 3.4 and 79 for the PR- and HPT-processed samples, respectively. According to previous studies, the higher the plastic deformation and hydrostatic pressure applied during deformation, the higher the density of vacancies in the material $[46,47]$. The excess vacancy concentration in pure $\mathrm{Cu}$ and Ni samples processed by HPT can achieve values of $(0.9-20)^{*} 10^{\wedge}(-4)[46,47]$, whereas in $\alpha^{\prime}$-martensite processed by HPT the equivalent value are $(5.2 \pm 3.6)^{*} 10^{\wedge}(-4)$ [48]. Since austenitic stainless steel is a material having a low stacking fault energy and a high melting temperature, one can predict that a high density of agglomerated vacancies will appear in the HPT-processed samples, as opposed to the PR-processed samples. This means that even though the vacancy concentration decreases with increasing pressure during annealing, in the HPT-processed samples it must be much higher than in the PRprocessed samples during annealing under high hydrostatic pressure, enabling dislocation climbing and the migration of grain boundaries even under a pressure of $6 \mathrm{GPa}$.

3. Thirdly, in the HPT-processed samples one can expect to find a high density of non-equilibrium grain boundaries. The specific structure of grain boundaries affects diffusivity, which is much higher than in the case of general high-angle grain boundaries and highly defected twin boundaries. It is also possible that there is a certain fraction of non-equilibrium grain boundaries present in the PR-processed samples, as it is highly deformed. Nevertheless, that value is much lower than in the HPT-processed samples. During annealing under $0.1 \mathrm{MPa}$, the rapid recovery of such boundaries may decrease their mobility. In contrast, under high pressure, such a rapid recovery may be suppressed, and the enhanced diffusivity and excess energy of the non-equilibrium boundaries may act as a driving force for grain growth.

\section{Does annealing under high hydrostatic pressure result in the same microstructure as under atmospheric pressure?}

In order to answer this question, experiments in which PR- and HPT-processed samples were annealed for 4 min under $0.1 \mathrm{MPa}$ were performed. The results were compared with the microstructures obtained for annealing under 2 and 6 GPa for $10 \mathrm{~min}$. It was discovered that, in the case of the PR-processed samples, the microhardness and microstructure after $4 \mathrm{~min}$ of annealing under $0.1 \mathrm{MPa}$ are comparable to the values obtained after $10 \mathrm{~min}$ under 2GPa. However, they differ slightly in the percentage of the recrystallized area, which is greater for the PR_10_2GPa-approximately $80 \%$ than the PR_4_0.1 MPa-approximately 70\%. The HPT-processed samples annealed for 4 min under $0.1 \mathrm{MPa}$ were fully recrystallized and can be compared with the samples annealed for $10 \mathrm{~min}$ under $6 \mathrm{GPa}$. However, they differ slightly in the value of the coefficient of variation, which is greater for the 
samples annealed under high hydrostatic pressure. This might result from the fact that under high pressure applied during annealing the migration of vacancies is highly reduced and various grain boundaries tend to migrate by various mechanisms and consequently at various rates [49].

\section{Conclusions}

1. HPT processing allows obtaining the nanograined austenitic stainless steel 316LVM, while ultrafine grained one (with a mixture of nanotwins and elongated deformation bands) can be obtained by a more conventional processing of PR.

2. Annealing under atmospheric pressure revealed that HPT-processed samples are more thermally stable when compared to PR-processed one. This was attributed to the more uniform microstructure of a HPT samples and their higher content of non-equilibrium grain boundaries, which have the tendency to a rapid recovery during heating drastically reducing the driving force for grain growth.

3. Annealing under high hydrostatic pressures of 2 and $6 \mathrm{GPa}$ retards the processes of recrystallization and grain growth in samples processed by both methods; however, the retardation is much more pronounced for a PR-processed samples. This was related to such microstructural features of HPT samples as a higher vacancy concentration, lower frequency of low-angle grain boundaries and higher fraction of non-equilibrium grain boundaries, which all enhance the mobility of grain boundaries under high pressure.

4. The microstructure reorganization during annealing under high pressure proceeds in the same way as during annealing under atmospheric pressure; however, for the latter the same grain size is obtained after shorter annealing time.

\section{Acknowledgements}

This work was supported by Polish NSC project SONATA No. UMO-2014/15/D/ST8/00532.

Open Access This article is distributed under the terms of the Creative Commons Attribution 4.0
International License (http://creativecommons.org/ licenses/by/4.0/), which permits unrestricted use, distribution, and reproduction in any medium, provided you give appropriate credit to the original author(s) and the source, provide a link to the Creative Commons license, and indicate if changes were made.

\section{References}

[1] Doherty RD, Hughes DA, Humphreys FJ et al (1997) Current issues in recrystallization: a review. Mater Sci Eng A 238:219-274

[2] Rios PR, Siciliano FS, Sandim HRZ et al (2005) Nucleation and growth during recrystallization. Mater Res 8:225-238

[3] El-Tahawy M, Huang Y, Choi H et al (2017) High temperature thermal stability of nanocrystalline $316 \mathrm{~L}$ stainless steel processed by high-pressure torsion. Mater Sci Eng A 682:323-331

[4] Novikov VY (2015) Grain growth in nanocrystalline materials. Mater Lett 159:510-513

[5] Tang L, Zhao Y, Islamgaliev RK et al (2017) Microstructure and thermal stability of nanocrystalline $\mathrm{Mg}-\mathrm{Gd}-\mathrm{Y}-\mathrm{Zr}$ alloy processed by high pressure torsion. J Alloys Compd 721:577-585

[6] Valiev RZ, Islamgaliev RK, Alexandrov IV (2000) Bulk nanostructured materials from severe plastic deformation. Prog Mater Sci 45:103-189

[7] Lian J, Valiev RZ, Baudelet B (1995) On the enhanced grain growth in ultrafine grained metals. Acta Metall Mater 43:4165-4170

[8] Sauvage X, Wilde G, Divinski SV et al (2012) Grain boundaries in ultrafine grained materials processed by severe plastic deformation and related phenomena. Mater Sci Eng A 540:1-12

[9] Ivanov KV (2008) Characteristic features and thermal stability of molybdenum processed by different ways of severe plastic deformation. Mater Sci Forum 584-586:917-922

[10] Zhang Y, Ganeev AV, Gao X et al (2008) Influence of HPT deformation temperature on microstructure and thermal stability of ultrafine-grained tungsten. Mater Sci Forum 584-586:1000-1005

[11] Bazarnik P, Lewandowska M, Andrzejczuk M, Kurzydlowski KJ (2012) The strength and thermal stability of Al$5 \mathrm{Mg}$ alloys nano-engineered using methods of metal forming. Mater Sci Eng A 556:134-139

[12] Kotan H (2015) Microstructural evolution of 316L stainless steels with yttrium addition after mechanical milling and heat treatment. Mater Sci Eng A 647:136-143 
[13] Wang SJ, Jozaghi T, Karaman I et al (2017) Hierarchical evolution and thermal stability of microstructure with deformation twins in 316 stainless steel. Mater Sci Eng A 694:121-131

[14] Krawczynska AT, Brynk T, Gierlotka S et al (2013) Mechanical properties of nanostructured 316LVM stainless steel annealed under pressure. Mech Mater 67:25-32

[15] Gierlotka S, Grzanka E, Krawczynska A et al (2011) Strain relaxation and grain growth in 316LVM stainless steel annealed under pressure. Zeitschrift für Krist Proc $1: 281-286$

[16] Tyschenko IE, Volodin VA, Cherkov AG (2016) Enhanced germanium precipitation and nanocrystal growth in the $\mathrm{Ge}+$ ion-implanted $\mathrm{SiO} 2$ films during high-pressure annealing. Solid State Commun 247:53-57

[17] Ranjbar S, Menon MRR, Fernandes PA, Da Cunha AF (2015) Effect of selenization conditions on the growth and properties of $\mathrm{Cu} 2 \mathrm{ZnSn}(\mathrm{S}, \mathrm{Se}) 4$ thin films. In: Thin solid films. pp 188-192

[18] Liu J, Si Y, Gong Y et al (2017) Enhanced magnetic refrigeration performance in metamagnetic $\mathrm{MnCoSi}$ alloy by high-pressure annealing. J Alloys Compd 701:858-863

[19] Hillard JE, Lommel JM, Hudson JB, Stein DF, Livingston JD (1960) Effect of annealing under high pressure on dislocations in lithum fluoride, aluminium, copper and iron. Acta Metall 9:787-794

[20] Tanner LE, Radcliffe SV (1962) Effect of hydrostatic pressure on the kinetics of recrystallization in high-purity copper. Acta Metall 10:1161-1169

[21] Lojkowski W, Molodov DA, Gottstein G, Shvidlerman LS (1996) The mechanism of grain boundary migration in aluminium bicrystals. Mater Sci Forum 207-209:537-540

[22] Shvindlerman LS, Czubayko U, Gottstein G, Molodov DA (1996) High pressure effect on grain boundary migration and mechanism of grain boundary migration. Mater Sci Forum 204-206:45-54

[23] Syrenko AF, Klinishev GP, Khôi VT (1973) Recrystallization of copper under hydrostatic pressure up to $15 \mathrm{kbar}$. J Mater Sci 8:765-769. https://doi.org/10.1007/BF00553726

[24] Kühlein W, Stüwe HP (1988) The influence of high hydrostatic pressure on recrystallization of $\alpha$-brass. Acta Metall 36:3055-3059

[25] Lojkowski W (1988) On the effect of high pressures on the mobility of atoms in grain boundaries. $\mathrm{J}$ Phys-Paris 49:545-549

[26] Sursaeva V, Protasova S, Lojkowski W et al (1999) Microstructure evolution during normal grain growth under high pressure in 2-D aluminium foils. Texture Mictrostruct $32: 175-185$
[27] Hilliard JE, Lommel JM, Hudson JB, Stein DF, Livingston JD (1962) Effect of annealing under high pressures on dislocations in lithium fluoride, aluminum, copper and iron. Acta Metall Mater 9:787-794

[28] Dobatkin SV, Rybalchenko OV, Enikeev NA et al (2016) Formation of fully austenitic ultrafine-grained high strength state in metastable $\mathrm{Cr}-\mathrm{Ni}-\mathrm{Ti}$ stainless steel by severe plastic deformation. Mater Lett 166:276-279

[29] Edalati K, Horita Z (2016) A review on high-pressure torsion (HPT) from 1935 to 1988. Mater Sci Eng A 652:325-352

[30] Dong FY, Zhang P, Pang JC et al (2015) Strength, damage and fracture behaviors of high-nitrogen austenitic stainless steel processed by high-pressure torsion. Scr Mater 96:5-8

[31] Valiev RZ, Estrin Y, Horita Z et al (2006) Producing bulk ultrafine-grained materials by severe plastic deformation. J Microsc 58:33-39

[32] Vorhauer A, Pippan R (2004) On the homogeneity of deformation by high pressure torsion. Scr Mater 51:921-925

[33] Valiev RZ, Estrin Y, Horita Z et al (2016) Producing bulk ultrafine-grained materials by severe plastic deformation: 10 years later. JOM 68:1216-1226

[34] Khvostantsev LG, Vereshchagin LF, Novikov AP (1997) A verkh-niz (up-down) toroid device for generation of high pressure. High Temp-High Press 9:637

[35] Khvostantsev LG, Slesarev VN, Brazhkin VV (2004) Toroid type high-pressure device: history and prospects. High Press Res 24:371-383

[36] Wejrzanowski T, Spychalski W, Różniatowski K, Kurzydłowski K (2008) Image based analysis of complex microstructures of engineering materials. Int J Appl Math Comput Sci 18:33-39

[37] Wejrzanowski T, Lewandowska M, Kurzydłowski KJ (2010) Stereology of nano-materials. Image Anal Stereol 29:1-12

[38] Guy K, Butler EP, West DRF (1982) $\varepsilon$ and $\alpha^{\prime}$ martensite formation and reversion in austenitic stainless steels. J Phys Colloq 43:575-580

[39] Rathmayr GB, Hohenwarter A, Pippan R (2013) Influence of grain shape and orientation on the mechanical properties of high pressure torsion deformed nickel. Mater Sci Eng A 560:224-231

[40] Pippan R, Scheriau S, Taylor A et al (2010) Saturation of fragmentation during severe plastic deformation. Annu Rev Mater Res 40:319-343

[41] Humphreys FJ, Hatherly M (1996) Recrystallization and related annealing phenomena. Pergamon Press, Oxford

[42] Belyakov A, Sakai T, Miura H et al (2002) Continuous recrystallization in austenitic stainless steel after large strain deformation. Acta Mater 50:1547-1557 
[43] Renk O, Hohenwarter A, Eder K et al (2015) Increasing the strength of nanocrystalline steels by annealing: is segregation necessary? Scr Mater 95:27-30

[44] Valiev RZ (2003) Paradoxes of severe plastic deformation. Adv Eng Mater 5:296-300

[45] Winning M, Schäfer C (2006) Influencing recrystallization behaviour by mechanical loads. Mater Sci Eng A 419:18-24

[46] Setman D, Schafler E, Korznikova E, Zehetbauer MJ (2008) The presence and nature of vacancy type defects in nanometals detained by severe plastic deformation. Mater Sci Eng A 493:116-122
[47] Zehetbauer MJ, Steiner G, Schafler E, Korznikov A, Korznikova E. In Horita Z (ed) Proceedings of the 3rd international conference on nanomaterials by severe plastic deformation, Fukuoka, Japan (2005) Mater Sci Forum 503-504: 57-64

[48] El-Tahawy M, Huang Y, Um T et al (2017) Stored energy in ultrafine-grained $316 \mathrm{~L}$ stainless steel processed by highpressure torsion. J Mater Res Technol 6:336-347

[49] Winning M, Gottstein G, Shvindlerman LS (2002) On the mechanisms of grain boundary migration. Acta Mater 50:353-363 